\title{
Vitamin D deficiency and autism; a review on recent findings
}

\author{
Nemat Sotodehasl ${ }^{1}$, Mohammad Reza Tamadon ${ }^{2 *}$, Farhad Malek ${ }^{2}$
}

\begin{abstract}
Autism is a group of lifelong developmental disabilities with various genetic and environmental risk factors which is generally not curable. The proportion of children with autism spectrum disorders (ASDs) has risen over the past decade. Few studies have focused on vitamin D status of patients with autism. Therefore, this study was aimed to further investigate the relationship between vitamin D deficiency and autism. In this short review, we discuss the relationship between vitamin D deficiency and ASDs. Our literature review yielded over 80 articles published since 2006 in the electronic databases of the Web of Knowledge, EBSCO, OVID and PubMed. As the results showed, no significant difference between children with and without autism regarding vitamin D serum levels was obtained. According to the controversial results on the correlation of vitamin D serum value and autism in children with ASD, it is necessary to conduct further studies in this field.

Keywords: Vitamin D Deficiency, Children, Autism spectrum disorders, Oxidative stress

Please cite this paper as: Sotodehasl N, Tamadon MR, Malek F. Vitamin D deficiency and autism; a review on recent findings.. J Parathyr Dis. 2018;6(1):7-12. DOI: 10.15171/jpd.2018.04.

Copyright ( 2018 The Author(s); Published by Nickan Research Institute. This is an open-access article distributed under the terms of the Creative Commons Attribution License, which permits unrestricted use, distribution, and reproduction in any medium, provided the original work is properly cited.
\end{abstract}

\section{Introduction}

Autism spectrum disorder (ASD) is a neurodevelopmental disorder which usually develops in early 3 years of life. ASDs are a heterogeneous group of complex biological and neurodevelopment diseases (1-3).

ASD, with an unknown etiology, remains poorly understood and has no specific treatment. The prevalence of ASD has increased over the past decade and is continuously increasing. This condition made its medical management a challenging task. However, it is unclear whether the increase of its prevalence is due to changes in diagnosis or a true increase in proportion of cases $(4,5)$.

ASDs were first labeled as 'autism' by Leo Kenner in 1943 -- a child psychiatrist (6).

Autism is a group of lifelong developmental disabilities with multiple genetic and environmental risk factors which is generally not curable. The people with autism suffer from impaired social interaction and problems in verbal and nonverbal communication. In recent years, there has been a remarkable rise in the prevalence of autism. The increase in prevalence of autism may not only due to an improvement in diagnostic techniques and the rise of people's awareness (7). This disease is associated with other neuro-behavior-cognitive disorders. Its symptoms include a wide range of socio-communication problems, intelligent disabilities, speech problems, attention deficit hyperactivity, seizure disorder, fragile $\mathrm{X}$ syndrome, or tuberous sclerosis. Moreover, some children may also have various mental health problems such as depression or anxiety (8).

Ming et al and Gonzalez et al detected that ASDs often has a multitude of biological features too. These biological features include systemic pathophysiological disturbances such as increasing oxidative stress, mitochondrial dysfunction, and metabolic or immune abnormalities $(9,10)$.

The interaction of genetic and environmental parameters in ASD was investigated in recent years. Lack of vitamin $\mathrm{D}$ has newly been suggested as a probable environmental risk factor for autism (11).

Vitamin D deficiency is now recognized as a pandemic problem. Vitamin D deficiency mainly occurs due low sun exposure, while it is the main source of vitamin $D$ for humans. Vitamin D is a hormone produced in the skin. It has a hormone-like effect on all tissues of the body. Vitamin $\mathrm{D}$ regulates bone metabolism, calcium absorption, gene expression, cell replication, differentiation, and death. Vitamin D has a pivotal role in prevention of cancers. Vitamin D has two different compounds including cholecalciferol found mainly in plants, and ergocalciferol found mainly in animals. To start the production of vitamin $\mathrm{D}$, the skin must be exposed to ultraviolet sunlight

Received: 9 March 2017, Accepted: 3 July 2017, ePublished: 20 July 2017

${ }^{1}$ Nursing Care Research Center, Semnan University of Medical Sciences, Semnan, Iran. ${ }^{2}$ Department of Internal Medicine, Kowsar Hospital, Semnan University of Medical Sciences, Semnan, Iran.

*Corresponding author: Mohammad Reza Tamadon, Email: mrt_tamadon@yahoo.com 
Implication for health policy/practice/research/ medical education

In this review paper we found no significant difference of vitamin D between children with and without ASDs. Moreover, the value of vitamin $\mathrm{D}$ has no meaningful correlation with the intensity of ASDs. However, further studies on this aspect of autism is necessary.

and at the end develops an active form of vitamin-calcitriol (1,25-(OH)2D3) (12).

Vitamin D deficiency causes rickets, osteoporosis, osteopenia, and osteomalacia (bone and body pains). Additionally vitamin D deficiency plays a key role in multiple sclerosis, rheumatoid arthritis, many cancers, depression, autism, falls, heart diseases such as congestive heart failure, type 1 diabetes, high blood pressure, fibromyalgia, chronic fatigue syndrome, parkinsonism, bacterial vaginosis, $\mathrm{C}$-sections, chronic headaches, chronic back pain, osteoarthritis, allergies, eczema, melanoma, psoriasis and gum disease. Appropriate levels of vitamin $\mathrm{D}$ boost immune system and protect human against colds and flu (13). Levels of 25(OH)D are applied to determine the status of vitamin D level in every individual (14).

It has been suggested that vitamin $\mathrm{D}$ hormone plays a role in autism while there is an association between the incidence of autism and low levels of vitamin D $(15,16)$.

Vitamin $\mathrm{D}$ has a position in neuro-differentiation, gene regulation, embryogenesis, neuro-immunity, and antioxidant and also anti-apoptosis effects (17-22). A relatively small proportion of studies have focused on the status of vitamin $\mathrm{D}$ in patients with autism. The present study aimed to further investigate the potential role of vitamin $\mathrm{D}$ in autism by measuring the levels of both circulating forms of vitamin D [25(OH)D and $(1,25(\mathrm{OH}) 2 \mathrm{D} 3)]$ and calcium in children with ASD and to compare them with age-matched normal controls. We also examined the relationship between vitamin D status, birth season, and clinical characteristics of autism.

\section{Methods}

This study sought to review the possible relationship between ASDs with status vitamin $\mathrm{D}$.

Based on our search strategy, we searched for the following keywords: vitamin D, ergocalciferol, vitamin D2, cholecalciferol, vitamin D3, calcitriol, vitamin 1,25 D3 , 25-hydroxyvitamin D, 25-OHD , 25-hydroxy vitamin $\mathrm{D}$ and autism or autism spectrum disorder.

\section{Evidence acquisition}

ASD has long been considered to be a psychiatric or neurological brain-based disorder (23).

Autism also has a genetic/environmental source. According to recent studies, one of the possible risk factor in the development of ASD is vitamin D deficiency. Several studies point out that autism is a neuro-inflammatory disease $(24,25)$. According to previous studies, vitamin D has a strong anti-inflammatory effect (26). Experimental models have shown that vitamin $\mathrm{D}$ has both direct and indirect anti-inflammatory impacts which strengthens both arms of the immune system (innate immunity and adaptive immunity) (27-29). A recent research reveals that activated vitamin $\mathrm{D}$ has multiple anti-inflammatory effects (30). For example, vitamin D inhibits the synthesis and biological actions of pro-inflammatory prostaglandins which are elevated in autism $(27,31)$. Vitamin D also shows its anti-inflammatory effects through the inhibition of nuclear factor-kappa $B$, which is involved in abnormal signaling in autistic brains $(32,33)$. It is a complex neurodevelopment disorder with various genetic and environmental risk factors including systemic pathophysiological disturbances (such as oxidative stress, mitochondrial dysfunction and metabolic and immune abnormalities $(9,10)$. During the past decade, numerous progresses have been made toward aspects of vitamin $\mathrm{D}$. Clinical trials show that vitamin D supplementation even at levels higher than previously recommended is beneficial for various conditions. It prevents cardiovascular disease and reduces the symptoms of colds or influenza. It has an ameliorative impact on diabetes mellitus, multiple sclerosis, Crohn's disease, pain, depression, and possibly autism. Recent studies have shown that lack of vitamin D in the period of pregnancy and/or early infancy is one of the likely risk factor which plays a role in development of autism $(34,35)$. In addition, maternal/neonatal vitamin $\mathrm{D}$ inadequacy has recently been suggested as a probable environmental risk factor for ASDs, while it is also interacted in early neurodevelopment, immune system, and gene regulation processes $(18,36,37)$.

Various processes in the body are affected by vitamin $\mathrm{D}$, which brain homeostasis, embryogenesis and neurodevelopment, immunological modulation (including the brain's immune system), ageing interacted in gene regulation $(18,19,38)$. In addition to these effects, vitamin $\mathrm{D}$ is now supposed to be involved in numerous other functions. It has been shown that vitamin $\mathrm{D}$ binds to more than 2700 genes and regulates the expression of more than 200 genes (18). Vitamin D has also a role in healing processes and reducing the risk of cell malignancy (19). Vitamin D deficiency is a likely risk factor interacted in neurodevelopment illnesses like schizophrenia and autism during the prenatal period $(18,19,35,38-40)$. Some studies addressed the level of active forms of vitamin $\mathrm{D}$ to be lower in autistic children which is indicative the possible role of this vitamin in autism disorder $(11,41)$.

According to the increasing prevalence of autism disorder and also based on previous studies proving the role of vitamin $\mathrm{D}$ inadequacy in the period of pregnancy and infancy in the incidence of this disorder, treating the patients by the administration of adequate amounts of this vitamin are suggested. However, proper studies have not been conducted in our country. In fact, adequate administration of vitamin $\mathrm{D}$ reduces autistic behaviors in severely deficient children. Likewise, maternal vitamin D deficiency may predispose children to autism (34,41-44). 


\section{Discussion}

There was no significant difference between babies with and without ASD regarding vitamin D serum level (45). The results of previously studies regarding the relationship between vitamin D serum levels and ASDs are controversial. However, Bromley et al showed vitamin $\mathrm{D}$ deficiency in the period of pregnancy is associated with increased risk of ADS in childhood (46).

Vitamin D deficiency has been suggested as a likely risk factor for developing ASD. Vitamin D levels may also be related to serotonin levels in the brain. Low levels of vitamin $\mathrm{D}$ during fetal and neonatal development could be as a result of poor TPH2 expression and consequently diminish serotonin concentrations in the developing brain (47). Strengthened values of inflammatory cytokines are observed in individuals with autism (48). Inflammatory cytokines such as CRP, IL-10 and IL-6 are boosted in people with vitamin D inadequacy (49). Vitamin D enhances glutathione in the brain, proposing a role of the hormone in brain detoxification pathways $(50,51)$. Depakote is associated with autism in children born of mothers taking this drug during pregnancy (52). Depakote is capable of reducing vitamin D values (53). Seizures are popular in children with autism (54). Stabilization of plasma vitamin $\mathrm{D}$ value has an anticonvulsant influence (55). Numakawa et al highlighted that autistic children had significantly lower 25-hydroxy vitamin D serum levels than healthy children $(P<0.001)$ (56). Serum 25-hydroxy vitamin D level had meaningful negative correlation with infantile autism rating scale $(P<0.001)(57)$. These findings suggest that low prenatal vitamin $\mathrm{D}$ may act as a risk factor for ASD. However, larger studies are required to examine this hypothesis. On the other hand, future studies should clear whether or not adequate vitamin $\mathrm{D}$ supplementation in pregnant women might lower the risk of ASDs in babies $(58,59)$. Serotonin and vitamin D have been suggested to play a role in autism. However, no causal mechanism has been explained. Supplementation with vitamin D and tryptophan is a practical and affordable solution to prevent autism and possibly ameliorate some symptoms of the disorder (47). It should be noted that autism has multifactorial etiology including hereditary and environmental triggers accompanied by gastrointestinal disorders, such as chronic duodenitis, gastritis, reflux esophagitis, intestinal lymphoid dysplasia, dysbiosis, excessive intestinal permeability, and yeast overgrowth (60).

Accordingly, autistic infants may have an influencing genetic abnormality. The presentation of the genotype is affected by various environmental parameters. Hypovitaminosis $\mathrm{D}$ is a probable risk factor for neurodevelopmental disturbances. Indeed, vitamin D acts as a neurosteroid. It is a strong up-regulator of neuronal growth factor. Vitamin D is detected broadly in brain tissue in the initial states embryogenesis. This hormone presents immunomodulation, neuroprotection and antiepileptic properties (47). Prenatal, postnatal and even and neonatal vitamin $\mathrm{D}$ supplementation is imperative for ordinary brain activities (47-60).

The noticeable rise in the frequency of autism across the last 20 years is due to an increase in medical cautions to avoid the sun exposure because of its increasing of skin cancers. Reduced sun exposure probably reduces vitamin $\mathrm{D}$ serum values and theoretically decreases activated levels of vitamin D in growing brains. Autism is more prevalent in dark-skinned people (59-62). Moreover, rigorous maternal vitamin D inadequacy is remarkably more prevalent in dark-skinned people. Vitamin D fortification in autistic infants ameliorates various brain functions. The rate of autism elevates when children watch television for a longer time or when it rains further. Both concerns diminish vitamin $\mathrm{D}$ construction. If lack of vitamin $\mathrm{D}$ deficiency is interacted in autism, symptoms should ameliorate in summer. Recent investigations detected a dramatic amelioration in both sleep and behavioral disturbances during the summer $(61,63)$. It should be remembered that dark-skinned people are weak to produce adequate vitamin $\mathrm{D}$ and they are more affected by autism. Recent studies have shown that $96 \%$ of pregnant black women and $63 \%$ of pregnant white women do not have adequate vitamin D serum levels. Autism may extend due to gestational and early infantile vitamin D insufficiency, and lack of adequate to sun exposure. This condition is unfortunately unsuccessful to balance due to existence of the epidemic of vitamin D insufficiency $(44,62)$. Every hypothesis on the etiology should consider its potent genetic basis and explain how genetic factors interrelate with the environment to cause the unusual epidemiology of autism. Activated vitamin D3 has a strong pleiotropic neurosteroid hormone which plays a significant role in mammalian brain growth. Rigorous vitamin D deficiency in the period of pregnancy, significantly disturbs the development of the baby structure and brain growth (6062). The physiology of calcitriol is exceptional amongst the steroid hormones while normal steroid feedback inhibition does not control neural levels of calcitriol. The obvious dramatic rise in the occurrence of autism during the last 20 years communicates to growing medical cautions to avoid sun exposures. These cautions may have considerably dropped brain vitamin D levels. Rigorous maternal vitamin D insufficiency results in rat pups with enlarged brain size and distended ventricles. These deformities are similar to those detected in autistic infants. Children with Williams syndrome, who may experience highly elevated calcitriol serum values in early infancy, commonly have phenotypes which are the opposite to the autism (60-64). Accordingly, estrogen and testosterone have very diverse impacts on the metabolism of vitamin D3 that may describe the noticeable difference in male/female gender ratios in autism. Calcitriol downregulates the creation of inflammatory cytokines in the brain tissue which is accompanied by autism. Lack of vitamin D disturbs glutathione metabolism. This condition explains the link between autism and oxidative stress (58-64). Likewise, taking vitamin D containing fish foods in the period of pregnancy lowers autistic symptoms 
in children. Additionally, autism is more popular in poleward latitudes. Similarly, autism is further popular in dark-skinned persons. In fact, significant maternal vitamin $\mathrm{D}$ inadequacy is remarkably common among African-Americans, irrespective of prenatal vitamin administration (62-66).

Vitamin D inadequacy dysregulates 36 proteins interacted in mammalian brain development. Furthermore, various biological routes for cytoskeleton maintenance, calcium homeostasis, oxidative phosphorylation, posttranslational modification, synaptic plasticity, neurotransmission, redox balance and chaperoning are affected by vitamin $\mathrm{D}$ inadequacy (64-68).

Based on some evidences, immunologic dysfunction, improper diet, nutritional and various vitamin deficiencies could contribute to several behavioral and perhaps cognitive symptoms in ASD. Both the brain and plasma of autistic subjects may show evidences of continuing a state of chronic micro-inflammation and presence of oxidative stress. Vitamin D has strong anti-inflammatory effects. A number of brain functions in autistic children improve by vitamin D supplementation (60-65). Considering vitamin $\mathrm{D}$ hypothesis of autism, taking of vitamin D-rich fish in the period of pregnancy is expected to ameliorate the offspring's mentation. As mentioned above autism could be due to gestational and early childhood vitamin $\mathrm{D}$ inadequacy (60-68). This situation may be an iatrogenic inadequacy as a result of medical cautions to prevent the sun exposure that unfortunately unsuccessful to compensate for the subsequent epidemic of vitamin D inadequacy (3-9,61).

Recently much attention has been made toward the role of vitamin $\mathrm{D}$ in health benefits beyond its effects on bone mineralization. It has been also stated that vitamin $\mathrm{D}$ decreases the frequency of cancers, inhibits viral illnesses, stabilizes mood disorders such as depression and heals musculoskeletal pains $(9,23)$.

Vitamin D is considered to play a role in numerous other functions. Vitamin D is also known to be involved in healing processes by reducing the risk of cell malignancy (19).

Although autism has long been considered to be a psychiatric or neurological brain-based disorder (23), Ming et al and Gonzalez et al argued that ASDs frequently have several biological characteristics, comprising systemic pathophysiological disruptions like mitochondrial dysfunction, metabolic and immune abnormalities and also oxidative stress $(9-11,23)$. In fact, the association between autism and immune dysfunction (66-68), and much increased rate of ASDs among dark skinned children living at Northern latitudes (66-68) are findings addressing the potential role for vitamin $\mathrm{D}$ in autism. Similar to other neuro-developmental disabilities, ASDs are generally not treatable, thus they require continuous management. However, outcomes are inconsistent and specific behavioral features changes over time. Many babies with ASDs remain as adults and, irrespective of their intellectual functioning, continue to experience problems during their life $(63,64)$. It is still controversial whether the prevalence of ASDs is increasing or the higher reported rate observed in recent years are due to the raise in people's awareness, changing diagnostic trends, and the use of more sensitive diagnostic tools (44). Nonetheless, a large part of ASD research has recently been focused on gene-environment interaction (65-67).

According to the findings of McGrath et al (68) and Cannell et al $(35,36)$ vitamin $\mathrm{D}$ is a powerful up-regulator of nerve growth factor. They pointed out that vitamin D receptor is detectable in a broad variety of brain tissues very early during embryogenesis (68). Kalueff and Tuohimaa assessed the brain-enhancing properties of vitamin D. They found the significant role of perinatal vitamin $\mathrm{D}$ adequacy in mothers as well as sufficient vitamin $\mathrm{D}$ supplementation for the child and their effects on normal brain functioning (62).

\section{Conclusion}

In this review paper we found no significant difference of vitamin D between children with and without ASDs. Moreover, the value of vitamin D has no meaningful correlation with the intensity of autism spectrum disorders. However, further studies on this aspect of autism is necessary.

\section{Authors' contribution}

NS searched and gathered the related articles as well as writing. MRT prepared the draft. FM edited the final manuscript. All authors read and signed the final paper.

\section{Conflicts of interest}

The authors declare no conflict of interest.

\section{Ethical considerations}

Ethical issues (including plagiarism, data fabrication, double publication) have been completely observed by the authors.

\section{Funding/Support}

None.

\section{References}

1. Mefford HC, Batshaw ML, Hoffman EP. Genomics, intellectual disability, and autism. N Engl J Med. 2012; 366:733-43. doi: 10.1056/NEJMra1114194

2. Deth RM, Benzecry C, Power-Charnitsky J, Waly VA. How environmental and genetic factors combine to cause autism: a redox/methylation hypothesis. Neurotoxicology. 2008; 29:190-201. doi: 10.1016/j.neuro.2007.09.010

3. Grabrucker AM. Environmental factors in autism. Front Psychiatry. 2012;3:118. doi: 10.3389/fpsyt.2012.00118

4. American Psychiatric Association. Diagnostic and statistical manual of mental disorders: DSM-IV. 4th ed. 1994, Washington (DC): APA; 1994.

5. Johnson CP, Myers SM. Identification and evaluation of children with autism spectrum disorders. Pediatrics. 2007; 120:1183-215. doi: 10.1542/peds.2007-2361

6. Kanner L. Autistic disturbances of affective contact. Acta 
Paedopsychiatr. 1968; 35:100-36.

7. Fombonne E. The prevalence of autism. JAMA. 2003; 289:87-9.

8. Gillberg C. The ESSENCE in child psychiatry: Early Symptomatic Syndromes Eliciting Neurodevelopmental Clinical Examinations. Res Dev Disabil. 2010; 31:1543-51. doi: 10.1016/j.ridd.2010.06.002

9. Ming X, Stein TP, Barnes V, Rhodes N, Guo L. Metabolic perturbance in autism spectrum disorders: a metabolomics study. J Proteome Res. 2012;11:5856-62. doi: 10.1021/ pr300910n

10. Gonzalez A, Stombaugh J, Lozupone C, Turnbaugh PJ, Gordon JI, Knight R. The mind-body-microbial continuum. Dialogues Clin Neurosci. 2011;13:55-62.

11. Kočovská E, Andorsdóttir G, Weihe P, Halling J, Fernell E, Stóra T, et al. Vitamin D in the General Population of Young Adults with Autism in the Faroe Islands. J Autism Dev Disord. 2014;44:2996-3005. doi: 10.1007/s10803-0142155-1

12. Adams DF. Vitamin D. 3rd ed. Amsterdam: Academic Press; 2011.

13. Holick MF. The vitamin D deficiency pandemic and consequences for nonskeletal health: mechanisms of action. Mol Aspects Med. 2008;29:361-8. doi: 10.1016/j. mam.2008.08.008

14. Cantorna MT, Zhu Y, Froicu M, Wittke A. Vitamin D status, 1,25-dihydroxyvitamin D3, and the immune system. Am J Clin Nutr. 2004;80:1717s-20s.

15. Wang T-T, Tavera-Mendoza LE, Laperriere D, Libby E, Burton MacLeod N, Nagai Y, et al. Large-scale in silico and microarray-based identification of direct 1,25-dihydroxyvitamin D3 target genes. J Mol Endocrinol. 2005;19:2685-95. doi: 10.1210/me.2005-0106

16. McCann JC, Ames BN. Is there convincing biological or behavioral evidence linking vitamin $\mathrm{D}$ deficiency to brain dysfunction? FASEB J. 2008;22:982-1001. doi: 10.1096/ fj.07-9326rev

17. Harms LR, Burne TH, Eyles DW, McGrath JJ. Vitamin $\mathrm{D}$ and the brain. Best Pract Res Clin Endocrinol Metab. 2011;25:657-69. doi: 10.1016/j.beem.2011.05.009

18. Ramagopalan SV, Heger A, Berlanga AJ, Maugeri NJ, Lincoln MR, Burrell A, et al. A ChIP-seq defined genomewide map of vitamin $\mathrm{D}$ receptor binding: associations with disease and evolution. Genome Res. 2010;20:1352-60. doi: 10.1101/gr.107920.110

19. Sigmundsdottir H. From the bench to the clinic: new aspects on immunoregulation by vitamin $\mathrm{D}$ analogs. Dermatoendocrinol. 2011;3:187-92.

20. McPartland J, Volkmar FR. Autism and related disorders. Handb Clin Neurol. 2012;106:407-18. doi: 10.1016/B978-0444-52002-9.00023-1

21. Harris SL, Jennett HK. Models of educational intervention for students with autism: home, center, and school-based programming. In: Volkmar FR, Klin A, Cohen D, eds. Handbook of Autism and Pervasive Developmental Disorders. 3rd ed. Hoboken, NJ: John Wiley \& Sons; 2005:1043-54.

22. Gupta K. Fungal infections and the kidney. Indian J Nephrol. 2001;11:147-54.

23. Polleux F, Lauder JM. Toward a developmental neurobiology of autism. Ment Retard Dev Disabil Res Rev. 2004;10:30317. doi: 10.1002/mrdd.20044

24. El-Ansary A, Al-Ayadhi L. Neuroinflammation in autism spectrum disorders. J Neuroinflammation. 2012;9:265. 10.1186/1742-2094-9-265

25. Depino AM. Peripheral and central inflammation in autism spectrum disorders. Mol Cell Neurosci. 2013;53:69-76. doi: 10.1016/j.mcn.2012.10.003

26. Guillot X, Semerano L, Saidenberg-Kermanac'h N, Falgarone G, Boissier MC. Vitamin D and inflammation. Joint Bone Spine. 2010;77:552-7. doi: 10.1016/j. jbspin.2010.09.018

27. Liu X, Nelson A, Wang X, Farid M, Gunji Y, Ikari J, et al. Vitamin D modulates prostaglandin E2 synthesis and degradation in human lung fibroblasts. Am J Respir Cell Mol Biol. 2014;50:40-50. doi: 10.1165/rcmb.2013-0211OC.

28. Olliver M, Spelmink L, Hiew J, Meyer-Hoffert U, HenriquesNormark B, Bergman P. Immunomodulatory effects of vitamin $\mathrm{D}$ on innate and adaptive immune responses to Streptococcus pneumoniae. J Infect Dis. 2013;208:1474-81. doi: 10.1093/infdis/jit355

29. Baeke F, Takiishi T, KorfH, Gysemans C, Mathieu C. Vitamin D: modulator of the immune system. Curr Opin Pharmacol. 2010;10:482-96. doi: 10.1016/j.coph.2010.04.001.

30. Krishnan AV, Feldman D. Molecular pathways mediating the anti-inflammatory effects of calcitriol: implications for prostate cancer chemoprevention and treatment. Endocr Relat Cancer. 2010;17:R19-38. doi: 10.1677/erc-09-0139.

31. Tamiji J, Crawford DA. The neurobiology of lipid metabolism in autism spectrum disorders. Neurosignals. 2010;18:98-112. doi: 10.1159/000323189.

32. Ziats MN, Rennert OM. Expression profiling of autism candidate genes during human brain development implicates central immune signaling pathways. PLoS One. 2011;6:e24691. doi: 10.1371/journal.pone.0024691.

33. Chen Y, Zhang J, Ge X, Du J, Deb DK, Li YC. Vitamin $\mathrm{D}$ receptor inhibits nuclear factor kappaB activation by interacting with IkappaB kinase beta protein. J Biol Chem. 2013;288:19450-8. doi: 10.1074/jbc.M113.467670.

34. Grant WB, Soles CM. Epidemiologic evidence supporting the role of maternal vitamin D deficiency as a risk factor for the development of infantile autism. Dermatoendocrinol. 2009;1:223-8.

35. Cannell JJ, Hollis BW. Use of vitamin D in clinical practice. Altern Med Rev 2008; 13:6-20. doi: 10.1016/j. mehy.2007.08.016.

36. Cannell JJ, Grant WB. What is the role of vitamin D in autism? Dermatoendocrinol. 2013;5:199-204. doi: 10.4161/ derm.24356.

37. Eyles DW, Burne TH, McGrath JJ. Vitamin D, effects on brain development, adult brain function and the links between low levels of vitamin $\mathrm{D}$ and neuropsychiatric disease. Front Neuroendocrinol. 2013;34:47-64. doi: 10.1016/j.yfrne.2012.07.001.

38. Eyles DW, Feron F, Cui X, Kesby JP, Harms LH, Ko P, et al. Developmental vitamin D deficiency causes abnormal brain development. Psychoneuroendocrinology. 2009;34 Suppl 1:S247-57. doi: 10.1016/j.psyneuen.2009.04.015.

39. McGrath J. Is it time to trial vitamin D supplements for the prevention of schizophrenia? Acta Psychiatr Scand. 2010;121:321-4. doi: 10.1111/j.1600-0447.2010.01551.x.

40. Gentile I, Zappulo E, Militerni R, Pascotto A, Borgia G, Bravaccio C. Etiopathogenesis of autism spectrum disorders: fitting the pieces of the puzzle together. Med Hypotheses. 2013;81:26-35. doi: 10.1016/j.mehy.2013.04.002.

41. Meguid NA, Hashish AF, Anwar M, Sidhom G. Reduced 
serum levels of 25-hydroxy and 1,25-dihydroxy vitamin D in Egyptian children with autism. J Altern Complement Med. 2010;16:641-5. doi: 10.1089/acm.2009.0349.

42. Saad K, Abdel-Rahman AA, Elserogy YM, Al-Atram AA, Cannell JJ, Bjorklund G, et al. Vitamin D status in autism spectrum disorders and the efficacy of vitamin D supplementation in autistic children. Nutr Neurosci. 2016;19:346-51. doi: 10.1179/1476830515y.0000000019.

43. Cannell JJ. On the aetiology of autism. Acta Paediatr. 2010;99:1128-30. doi: 10.1111/j.1651-2227.2010.01883.x.

44. Cannell JJ. Autism and vitamin D. Med Hypotheses. 2008;70:750-9. doi: 10.1016/j.mehy.2007.08.016.

45. Hashemzadeh M, Moharreri F, SOltanifar A. Comparative study of vitamin D levels in children with autism spectrum disorder and normal children: A case-control study. Journal of Fundamentals of Mental Health. 2015;17:197-201. doi: 10.22038/jfmh.2015.4578

46. Bromley RL, Mawer G, Clayton-Smith J, Baker GA. Autism spectrum disorders following in utero exposure to antiepileptic drugs. Neurology. 2008;71:1923-4. doi: 10.1212/01.wnl.0000339399.64213.1a

47. Patrick RP, Ames BN. Vitamin D hormone regulates serotonin synthesis. Part 1: relevance for autism. FASEB J. 2014;28:2398-413. doi: 10.1096/fj.13-246546

48. Ashwood P, Krakowiak P, Hertz-Picciotto I, Hansen R, Pessah I, Van de Water J. Elevated plasma cytokines in autism spectrum disorders provide evidence of immune dysfunction and are associated with impaired behavioral outcome. Brain Behav Immun. 2011;25(1):40-5.

49. Arnson Y, Itzhaky D, Mosseri M, Barak V, Tzur B, AgmonLevin $\mathrm{N}$, et al. Vitamin D inflammatory cytokines and coronary events: a comprehensive review. Clin Rev Allergy Immunol. 2013;45:236-47. doi: 10.1007/s12016-013-8356-0

50. Rose S, Melnyk S, Pavliv O, Bai S, Nick TG, Frye RE, et al. Evidence of oxidative damage and inflammation associated with low glutathione redox status in the autism brain. Transl Psychiatry. 2012;2:e134. doi: 10.1038/tp.2012.61.

51. Garcion E, Wion-Barbot N, Montero-Menei CN, Berger F, Wion D. New clues about vitamin D functions in the nervous system. Trends Endocrinol Metab. 2002;13:100-5.

52. Christensen J, Gronborg TK, Sorensen MJ, Schendel D, Parner ET, Pedersen LH, et al. Prenatal valproate exposure and risk of autism spectrum disorders and childhood autism. JAMA. 2013;309:1696-703. doi: 10.1001/jama.2013.2270

53. Tomita S, Ohnishi J, Nakano M, Ichikawa Y. The effects of anticonvulsant drugs on vitamin D3-activating cytochrome P-450-linked monooxygenase systems. J Steroid Biochem Mol Biol. 1991;39:479-85.

54. Deykin EY, MacMahon B. The incidence of seizures among children with autistic symptoms. Am J Psychiatry. 1979;136:1310-2. doi: 10.1176/ajp.136.10.1310.
55. Hollo A, Clemens Z, Kamondi A, Lakatos P, Szucs A. Correction of vitamin D deficiency improves seizure control in epilepsy: a pilot study. Epilepsy Behav. 2012;24:131-3. doi: 10.1016/j.yebeh.2012.03.011.

56. Numakawa T, Matsumoto T, Numakawa Y, Richards M, Yamawaki S, Kunugi H. Protective action of neurotrophic factors and estrogen against oxidative stress-mediated neurodegeneration. J Toxicol. 2011;2011:405194. doi: $10.1155 / 2011 / 405194$.

57. Mostafa GA, Al-Ayadhi LY. Reduced serum concentrations of 25-hydroxy vitamin D in children with autism: Relation to autoimmunity. J Neuroinflammation. 2012;9:201. doi: 10.1186/1742-2094-9-201.

58. Fernell E, Bejerot S, Westerlund J, Miniscalco C, Simila H, Eyles D, et al. Autism spectrum disorder and low vitamin D at birth: a sibling control study. Mol Autism. 2015;6:3. doi: 10.1186/2040-2392-6-3.

59. Kočovská E, Andorsdóttir G, Weihe P, Halling J, Fernell E, Stóra T, et al. Vitamin D in the general population of young adults with autism in the Faroe Islands. J Autism Dev Disord. 2014;44:2996-3005. doi: 10.1007/s10803-0142155-1.

60. Esparham AE, Smith T, Belmont JM, Haden M, Wagner LE, Evans RG, et al. Nutritional and Metabolic Biomarkers in Autism Spectrum Disorders: An Exploratory Study. Integr Med (Encinitas). 2015; 14:40-53.

61. Prevalence of autism spectrum disorders--autism and developmental disabilities monitoring network, six sites, United States, 2000. MMWR Surveill Summ. 2007;56:1-11.

62. Kalueff AV, Tuohimaa P. Neurosteroid hormone vitamin D and its utility in clinical nutrition. Curr Opin Clin Nutr Metab Care. 2007;10:12-9. doi: 10.1097/MCO.0b013e328010ca18

63. McPartland J, Volkmar FR. Autism and related disorders. Handb Clin Neurol. 2012;106:407-18. doi: 10.1016/B978-0444-52002-9.00023-1.

64. Howlin P, Goode S, Hutton J, Rutter M. Adult outcome for children with autism. J Child Psychol Psychiatry. 2004;45:212-29.

65. Freitag CM, Staal W, Klauck SM, Duketis E, Waltes R. Genetics of autistic disorders: review and clinical implications. Child Adolesc Psychiatry Ment Health. 2010;19:169-78. doi: 10.1007/s00787-009-0076-x.

66. Geier MR, Geier DA. Thimerosal in childhood vaccines, neurodevelopment disorders, and heart disease in the United States. J Am Physicians Surg. 2003;8:6-11.

67. Kirby D. Evidence of harm: mercury in vaccines and the autism epidemic: a medical controversy. 1st ed. New York: St. Martin's Press; 2005.

68. McGrath J, Feron F, Eyles D, Mackay-Sim A. Vitamin D: the neglected neurosteroid? Trends Neurosci. 2001;24:570-2. 